\title{
Optimal assessment of right ventricular function using cardiac magnetic resonance cine imaging after Mustard palliation for transposition of the great arteries
}

\author{
Laura Jimenez-Juan ${ }^{1 *}$, Subodh B Joshi ${ }^{2}$, Andrew T Yan², Susan H James ${ }^{1}$, Djeven Deva ${ }^{1}$, Elsie T Nguyen ${ }^{1}$, \\ Sebastian Ley', Andrew M Crean', Narinder Paul', Bernd J Wintersperger', Rachel M Wald ${ }^{1}$
}

From 2011 SCMR/Euro CMR Joint Scientific Sessions

Nice, France. 3-6 February 2011

\section{Objective}

To determine the reproducibility of axial versus short axis methods for measurement of right ventricular volumes and ejection fraction (RVEF) in adults after Mustard palliation for complete transposition of the great arteries (TGA).

\section{Background}

The most common cause of a systemic right ventricle is atrial redirection surgery (Mustard repair) in the setting of complete TGA. Decreased RVEF is common and is a predictor of morbidity and mortality. Cardiac magnetic resonance (CMR) cine imaging is the reference standard for assessment of right heart size and function. However, the optimal method of RV planimetry using CMR in patients with Mustard palliation for complete TGA remains unclear.

\section{Methods}

Consecutive adult patients with atrial redirection surgery (Mustard procedure) for complete TGA were identified from an existing database and steady state free-precession cine images acquired on $1.5 \mathrm{~T}$ commercially available scanners were reviewed. To obtain RVEF, both end-diastolic volumes (EDV) and end-systolic volumes (ESV) were measured in two orientations, axial and short axis, by two experienced, independent readers who were blinded to other results. One reader reanalyzed the RV volumes and function $\geq 14$ days after the first set of measurements. Intra- and inter-observer variabilities were determined using Bland-Altman analysis.

\section{Results}

A total of 25 patients ( 16 female, 9 male) were identified (median 31 years, interquartile range 26-37) between 2008 and 2010. All images had sufficient quality for analysis. From the axial stack, the medians (interquartile ranges) were RVEDV 243cc (198-297), RVESV 142cc (101-174) and RVEF 44\% (38-50). From the short axis stack, medians (interquartile ranges) were RVEDV 236cc (181-281), RVESV 127cc (90-157) and RVEF 44\% (41-50). Volumes derived from short axis and axial stacks were significantly different $(p=0.001$ for RVEDV and $\mathrm{p}<0.001$ for RVESV) but there was no statistical difference in RVEF between the methods ( $\mathrm{p}=0.38$ ). Bland Altman analysis for evaluation of intra and inter-observer variabilities are summarized in table 1 .

\section{Conclusion}

Following Mustard palliation for complete TGA, RVEF measurements derived from axial and short axis stacks are similar, although both RVEDV and RVESV values are significantly higher based on the axial acquisition. Intra-observer measurements appear to be more reliable using the axial as compared with the short axis method.

${ }^{1}$ Toronto General Hospital, Toronto, ON, Canada

Full list of author information is available at the end of the article

(c) 2011 Jimenez-Juan et al; licensee BioMed Central Ltd. This is an open access article distributed under the terms of the Creative 
Table 1 Comparison of axial and short axis RVEF measurements using Bland-Altman analysis

\begin{tabular}{llll}
\hline & Axial & & Short-axis \\
\hline Correlation co-efficient ( $p$ value) & Intra-observer & Inter-observer & Intra-observer \\
Bland-Altman bias & $0.88(p<0.001)$ & $0.76(p<0.001)$ & $0.82(p<0.001)$ \\
Limits of agreement & 0.92 & 3.29 & -0.24 \\
\hline
\end{tabular}

Author details

${ }^{1}$ Toronto General Hospital, Toronto, ON, Canada. ${ }^{2}$ St Michael's Hospital,

Toronto, ON, Canada.

Published: 2 February 2011

doi:10.1186/1532-429X-13-S1-O20

Cite this article as: Jimenez-Juan et al:: Optimal assessment of right ventricular function using cardiac magnetic resonance cine imaging after Mustard palliation for transposition of the great arteries. Journal of Cardiovascular Magnetic Resonance 2011 13(Suppl 1):O20.

Submit your next manuscript to BioMed Central and take full advantage of:

- Convenient online submission

- Thorough peer review

- No space constraints or color figure charges

- Immediate publication on acceptance

- Inclusion in PubMed, CAS, Scopus and Google Scholar

- Research which is freely available for redistribution

Submit your manuscript at www.biomedcentral.com/submit
C Biomed Central 